\title{
OPEN A host-directed macrocyclic peptide therapeutic for MDR gram negative bacterial infections
}

\begin{abstract}
Justin B. Schaal ${ }^{1 凶}$, Yoshihiro Eriguchi ${ }^{1,4,5}$, Dat Q. Tran ${ }^{1,2}$, Patti A. $\operatorname{Tran}^{1}{ }^{1}$, Chase Hawes ${ }^{1}$, Anthony E. Cabebe ${ }^{1}$, Kaitlyn Pike ${ }^{1}$, Katie Trinh ${ }^{1}$, André J. Ouellette ${ }^{1,3}$ \& Michael E. Selsted ${ }^{1,2,3}$

The emergence of infections by carbapenem resistant Enterobacteriaceae (CRE) pathogens has created an urgent public health threat, as carbapenems are among the drugs of last resort for infections caused by a growing fraction of multi-drug resistant (MDR) bacteria. There is global consensus that new preventive and therapeutic strategies are urgently needed to combat the growing problem of MDR bacterial infections. Here, we report on the efficacy of a novel macrocyclic peptide, minimized theta-defensin (MTD)-12813 in CRE sepsis. MTD12813 is a theta-defensin inspired cyclic peptide that is highly effective against CRE pathogens $K$. pneumoniae and $E$. coli in vivo. In mouse septicemia models, single dose administration of MTD12813 significantly enhanced survival by promoting rapid host-mediated bacterial clearance and by modulating pathologic cytokine responses, restoring immune homeostasis, and preventing lethal septic shock. The peptide lacks direct antibacterial activity in the presence of mouse serum or in peritoneal fluid, further evidence for its indirect antibacterial mode of action. MTD12813 is highly stable in biological matrices, resistant to bacterial proteases, and nontoxic to mice at dose levels 100 times the therapeutic dose level, properties which support further development of the peptide as a first in class anti-infective therapeutic.
\end{abstract}

Infections caused by CRE represent a global threat to human health. The Centers for Disease Control and Prevention (CDC) and the World Health Organization (WHO) categorize CRE infections as a major and urgent threat to public health. Resistance of CRE to carbapenem antibiotics leaves few treatment options other than colistin and polymyxin B, both of which have limited use because of their toxicities ${ }^{1,2}$. Among Enterobacteriaceae, infections by Klebsiella pneumoniae and Escherichia coli cause an estimated 140,000 nosocomial infections per year in the United States alone, and an increasing fraction are carbapenem resistant ${ }^{1}$. Of the $\beta$-lactam antibiotics, carbapenems have the broadest activity spectrum and greatest potency against Gram negative bacteria ${ }^{3-5}$. However, the incidence of CRE infections continues to rise in health care settings and in the community ${ }^{4,5}$, underscoring the need for new therapeutic countermeasures. In this regard, most efforts have focused on developing new carbapenem $/ \beta$-lactam-based drugs, some which are combined with $\beta$-lactamase inhibitors ${ }^{3}$. Carbapenem resistance is multifactorial, involving acquisition of new or mutant $\beta$-lactamases, efflux pumps, loss of outer membrane porins, and alterations of penicillin binding proteins ${ }^{6,7}$, and combinations of these resistance mechanisms broaden resistance to carbapenems and other antibiotics by $\mathrm{CRE}^{5}$, especially in K. pneumoniae.

Here we report a novel therapeutic strategy employing a macrocyclic peptide that is highly effective in a mouse model of CRE bacteremic sepsis. The peptide, MTD12813, acts by promoting host-mediated clearance of the pathogen by stimulating phagocytosis, while homeostatically modulating dysregulated systemic inflammation.

MTD12813 is a 14-amino acid macrocyclic peptide containing two disulfide bonds (Fig. 1) that possesses features of naturally occurring macrocyclic $\theta$-defensins expressed uniquely in myeloid and epithelial cells of Old World monkeys (OWM, e.g., rhesus macaques, baboons, vervets, cynomolgus monkeys) $)^{8,9}$ but not in other primates or non-primates. All known natural $\theta$-defensins are 18 -amino acid cyclic peptides containing three disulfides (Fig. 1) ${ }^{8-10}$ which confers remarkable stability in vitro and in vivo ${ }^{1-14}$. Studies show that $\theta$-defensins possess potent antimicrobial activities in vitro and unique anti-infective and immunoregulatory properties

\footnotetext{
${ }^{1}$ Department of Pathology and Laboratory Medicine, Keck School of Medicine, University of Southern California, Los Angeles, CA, USA. ${ }^{2}$ Oryn Therapeutics, Vacaville, CA, USA. ${ }^{3}$ Norris Comprehensive Cancer Center of the University of Southern California, Los Angeles, CA, USA. ${ }^{4}$ Present address: Department of Clinical Immunology and Rheumatology/Infectious Disease, Kyushu University Hospital, Fukuoka, Japan. ${ }^{5}$ Present address: Department of Medicine and Biosystemic Science, Kyushu University Graduate School of Medical Science, Fukuoka, Japan. ${ }^{\square}$ email: jschaal@usc.edu
} 


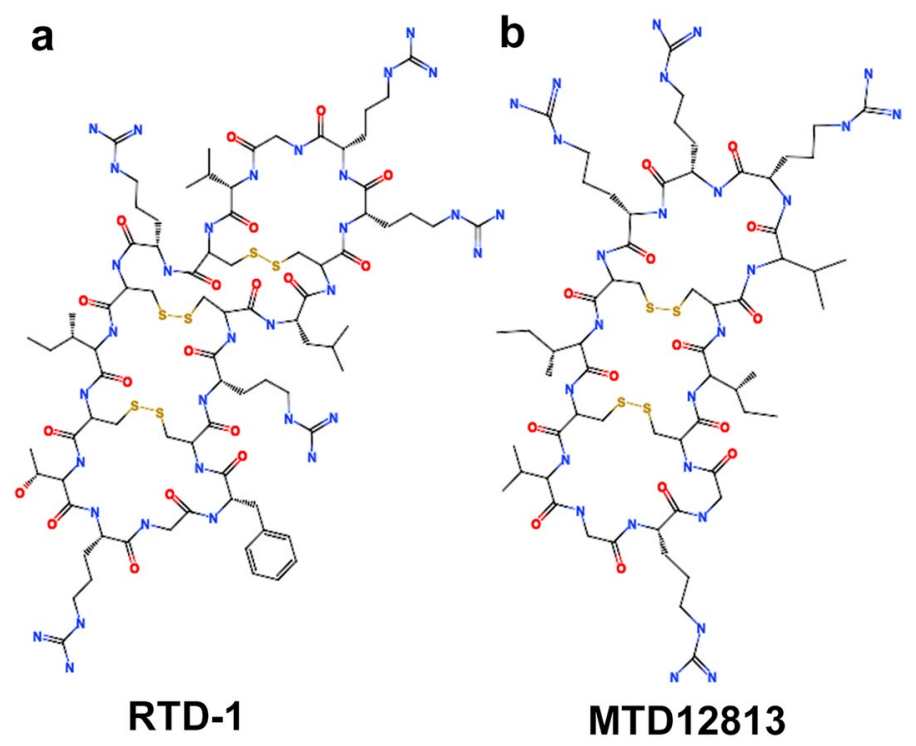

Figure 1. Natural Rhesus theta defensin 1 (RTD-1) and bioinspired MTD12813. Molecular structures of 18-amino acid RTD-1 (a) and 14-amino acid MTD12813 (b).

in vivo. The prototype rhesus macaque $\theta$-defensin ${ }^{14}$ RTD-1 (Fig. 1a) is effective in preclinical models of severe sepsis $^{11}$, systemic candidiasis ${ }^{15}$, SARS-CoV-1 infection ${ }^{16}$, chronic $P$. aeruginosa infection in cystic fibrosis ${ }^{12}$, endotoxin-induced lung injury ${ }^{17}$, and autoimmune arthritis $^{18}$. We and others have hypothesized that $\theta$-defensins contribute to the unique host defense and immunomodulatory responses of $\mathrm{OWM}^{19}$, primates that, compared to humans and other hominins, are intrinsically resistant to bacterial infections, endotoxemia, and sepsis ${ }^{20-23}$. In sepsis models, $\theta$-defensins facilitate host-mediated clearance of bacterial and fungal pathogens while moderating cytokine-driven immunopathology ${ }^{11,15,24}$. In a recent study, RTD-1 was highly effective in promoting fungal clearance in mice infected systemically with MDR C. albicans which resulted in markedly enhanced long-term survival ${ }^{15}$.

Building on insights into pharmacologic and biophysical properties of $\theta$-defensins, a library of minimized theta defensins (i.e., MTDs) was synthesized and evaluated for in vitro and in vivo properties in a multidimensional screen, details of which will be reported elsewhere. MTD12813 emerged as a promising lead for further preclinical evaluation as a therapeutic for MDR bacterial infections. Here we report that MTD12813 is efficacious in treatment of CRE sepsis in BALB/c mice and acts by stimulating host-mediated clearance of CRE pathogens through enhancement in phagocytosis and immune cell recruitment, while concomitantly modulating pathogenic cytokine responses.

\section{Results}

In vitro antibacterial activity of MTD12813. Minimum inhibitory concentrations (MICs) of MTD12813 and RTD-1 against a panel of CRE bacteria were determined and compared with carbapenem antibiotics (meropenem and imipenem), colistin, and polymyxin B. Test organisms included K. pneumoniae and $E$. coli strains expressing carbapenemases (KPC-2, NDM-1), extended-spectrum $\beta$-lactamase (ESBL) resistance factors as well as antibiotic sensitive reference strains (see Methods). Under standard CLSI assay conditions, the MIC of MTD12813 was 3.13-6.25 $\mu \mathrm{g} / \mathrm{ml}$ against CRE and non-CRE strains of K. pneumoniae and E. coli. MTD12813 was superior to RTD-1, and was as or more effective than meropenem and imipenem against each of the strains tested. As expected, colistin and polymyxin B were effective at low concentrations $(<0.78 \mu \mathrm{g} / \mathrm{ml})$ against all seven organisms. Of note, inclusion of $50 \%$ heat-inactivated mouse serum completely inhibited the activities of MTD12813 and RTD-1 against ${ }^{\mathrm{KPC}+} \mathrm{Kp}$ BAA-1705 $(\mathrm{Kp}-1705)(\mathrm{MIC}>100 \mu \mathrm{g} / \mathrm{ml})$, a finding consistent with a recent study of the antifungal activity of RTD- ${ }^{15}$. Similar to RTD-1, MTD12813 likely binds nonspecifically to plasma proteins, reducing the amount of free peptide available for a direct antimicrobial effect. In contrast, the antimicrobial activities of the conventional antibiotics tested were unaffected or slightly enhanced by addition of serum (Table 1 ).

MTD12813 promotes survival in MDR bacterial septicemia. Adult BALB/c mice were infected intraperitoneally with $K p-1705$, a virulent hypermucoid strain of $K$. pneumoniae (Methods) which results in rapid bacterial dissemination to blood, spleen, and other solid organs (liver, lungs, and kidneys; $10^{6}-10^{8} \mathrm{CFU} / \mathrm{g}$ ) within $1 \mathrm{~h}$ of infection (Supplemental Data Fig. 1). Kp-1705 infected mice showed clinical signs of systemic inflammatory response syndrome (SIRS) ${ }^{25}$, including diminished physical activity, hunched posture, piloerection, and altered breathing rates within $3 \mathrm{~h}$ of infection, and $\sim 75 \%$ of vehicle control mice succumbed or were humanely euthanized by $96 \mathrm{~h}$ post infection (p.i.). Peptide $(0.5,1.25$, or $5 \mathrm{mg} / \mathrm{kg}$ MTD12813) or saline treatment was initiated $1 \mathrm{~h}$ p.i.. A single dose of MTD12813 at 1.25 and $5 \mathrm{mg} / \mathrm{kg}$ dose levels resulted in $100 \%$ long 


\begin{tabular}{|c|c|c|c|c|c|c|c|c|c|c|c|c|c|c|}
\hline \multirow[b]{2}{*}{ Strain ID } & \multicolumn{8}{|c|}{ K. pneumoniae } & \multicolumn{6}{|l|}{ E. coli } \\
\hline & \multicolumn{2}{|c|}{ BAA-1705 } & \multicolumn{2}{|c|}{ BAA-2146 } & \multicolumn{2}{|c|}{700603} & \multicolumn{2}{|c|}{ BAA-1706 } & \multicolumn{2}{|c|}{ BAA-2340 } & \multicolumn{2}{|c|}{ BAA-2471 } & \multicolumn{2}{|l|}{ ML35 } \\
\hline MDR factor & \multicolumn{2}{|c|}{ KPC-2 } & \multicolumn{2}{|c|}{ NDM-1 } & \multicolumn{2}{|c|}{ ESBL } & \multicolumn{2}{|c|}{ none } & \multicolumn{2}{|c|}{ KPC-2 } & \multicolumn{2}{|c|}{ NDM-1 } & \multicolumn{2}{|l|}{ none } \\
\hline MTD12813 & 6.25 & $>100$ & 6.25 & $>100$ & 6.25 & $>100$ & 3.13 & $>100$ & 6.25 & $>100$ & 3.13 & 100 & 3.13 & $>100$ \\
\hline RTD-1 & $>100$ & $>100$ & 100 & $>100$ & $>100$ & $>100$ & $>100$ & $>100$ & 50 & $>100$ & 25 & $>100$ & 25 & $>100$ \\
\hline Meropenem & 50 & 50 & 100 & $>100$ & $<0.78$ & $<0.78$ & 1.56 & $<0.78$ & 6.25 & 6.25 & 50 & $>100$ & $<0.78$ & $<0.78$ \\
\hline Imipenem & $>100$ & 12.5 & $>100$ & 25 & $<0.78$ & $<0.78$ & 3.13 & $<0.78$ & 25 & 6.25 & 50 & 25 & $<0.78$ & $<0.78$ \\
\hline Colistin & $<0.78$ & $<0.78$ & $<0.78$ & $<0.78$ & $<0.78$ & $<0.78$ & $<0.78$ & $<0.78$ & $<0.78$ & $<0.78$ & $<0.78$ & $<0.78$ & $<0.78$ & $<0.78$ \\
\hline Polymyxin B & $<0.78$ & $<0.78$ & $<0.78$ & $<0.78$ & $<0.78$ & $<0.78$ & $<0.78$ & $<0.78$ & $<0.78$ & $<0.78$ & $<0.78$ & $<0.78$ & $<0.78$ & $<0.78$ \\
\hline
\end{tabular}

Table 1. MICs of MTD12813, RTD-1 and antibacterial drugs ( $\mu \mathrm{g} / \mathrm{ml})$. Italics columns are MICs in the presence of $50 \%$ heat inactivated mouse serum.
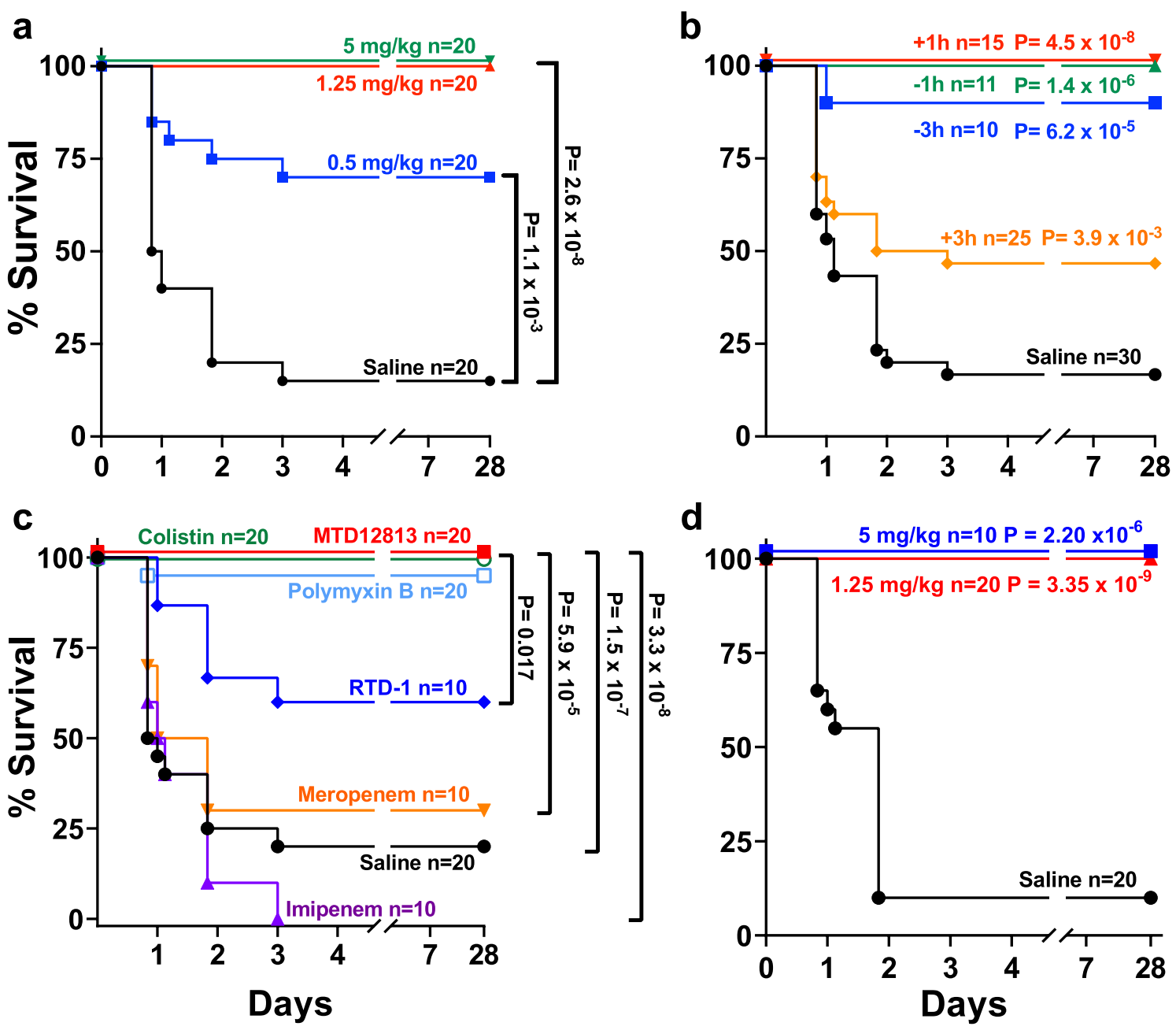

Figure 2. MTD12813 promotes survival in CRE bacteremic sepsis. (a-c) Mice were challenged i.p. with Kp$1705\left(3-5 \times 10^{8} \mathrm{CFU}\right)$ at $\mathrm{t}=0$. (a) One h post infection (p.i.) mice were treated i.p. with MTD12813 at 0.5, 1.25, $5 \mathrm{mg} / \mathrm{kg}$, or saline vehicle and monitored for up to $28 \mathrm{~d}$. (b) Mice were treated with a single i.p. injection of 1.25 $\mathrm{mg} / \mathrm{kg}$ MTD12813 before $(-1$ or $-3 \mathrm{~h})$ or after $(+1$ or $+3 \mathrm{~h})$ infection; controls received saline. P values compared to saline control. (c) Mice were treated $1 \mathrm{~h}$ p.i. with a single i.p. dose of $1.25 \mathrm{mg} / \mathrm{kg} \mathrm{MTD12813}$, meropenem, imipenem, colistin, or polymyxin B or $5 \mathrm{mg} / \mathrm{kg}$ RTD-1. (d) Mice were challenged i.p. with CRE E. coli BAA2340 (3- $\left.6 \times 10^{7} \mathrm{CFU}\right)$. One h after infection, mice received a single i.p. injection of 5 or $1.25 \mathrm{mg} / \mathrm{kg}$ MTD12813 or saline. $\mathrm{P}$ values determined by Fisher's exact test.

term ( $\geq 28$ days) survival $\left(\mathrm{P}=2.6 \times 10^{-8}\right)$ (Fig. $\left.2 \mathrm{a}\right)$. Compared to saline-treated controls, the clinical appearance/ activity of mice treated with MTD12813 at 1.25 or $5 \mathrm{mg} / \mathrm{kg}$ markedly improved within $24 \mathrm{~h}$ of treatment, and behavior and appearance were normal by $96 \mathrm{~h}$. Treatment efficacy, measured by survival, was reduced when the 
dose of MTD12813 was reduced to $0.5 \mathrm{mg} / \mathrm{kg}$, but survival benefit was still statistically significant compared to saline treatment $\left(\mathrm{P}=1.1 \times 10^{-3}\right)$.

The effect of timing of peptide treatment on $\mathrm{Kp}-1705$ infected mice was analyzed in experiments in which a single dose of $1.25 \mathrm{mg} / \mathrm{kg}$ MTD12813 was administered 1 or $3 \mathrm{~h}$ before or after i.p. infection (Fig. 2b). All infected mice in the $-1 \mathrm{~h}$ and $+1 \mathrm{~h}$ treatment cohorts survived long term $\left(\mathrm{P}<1 \times 10^{-6}\right)$, and nearly equivalent efficacy was obtained when mice were treated $3 \mathrm{~h}$ prior to infection. Even when treatment was initiated $3 \mathrm{~h}$ after infection, survival was enhanced (Fig. $2 \mathrm{~b} ; \mathrm{P}=3.9 \times 10^{-3}$ ). Notably, all mice in the $+3 \mathrm{~h}$ cohort showed clinical signs of SIRS (described above) before MTD12813 treatment, consistent with the high tissue burdens of $K p-1705$ in the blood and organs of infected mice (Supplemental Fig. 1). Moreover, as discussed below, plasma levels of proinflammatory cytokines were markedly elevated within $2-4 \mathrm{~h}$ of $K p-1705$ infection in mice, consistent with severe sepsis. Nevertheless, half of the $+3 \mathrm{~h}$ cohort were rescued by a single dose of MTD12813 and were long term survivors.

Comparison of MTD12813 and conventional antibiotics for efficacy in Kp-1705 septicemia. Equal single doses of MTD12813, imipenem, meropenem, colistin, and polymyxin B were administered i.p. $1 \mathrm{~h}$ after $\mathrm{Kp}-1705$ challenge (as in Fig. 2a,b). MTD12813 and colistin treatments resulted in $100 \%$ survival, and polymyxin B was $95 \%$ effective, but neither carbapenem provided significant survival benefit compared to saline treated controls. Lack of imipenem and meropenem benefit was expected given that Kp-1705 is highly resistant to carbapenems. Note the superior efficacy of $1.25 \mathrm{mg} / \mathrm{kg}$ of MTD12813 compared to $5 \mathrm{mg} / \mathrm{kg}$ of natural $\theta$-defensin RTD-1 in vivo (Fig. 2c).

Efficacy of MTD12813 against MDR E. coli. After Klebsiella spp., E. coli is the second most common cause of CRE infections ${ }^{1}$. Given the efficacy of MTD12813 against K. pneumoniae, we hypothesized that this peptide would be efficacious in E. coli septicemia. Mice were challenged i.p. with ${ }^{\mathrm{KPC}}{ }^{E}$. coli BAA-2340 and treated $1 \mathrm{~h}$ p.i. with a single injection of peptide at 1.25 or $5 \mathrm{mg} / \mathrm{kg}$. As shown in Fig. $2 \mathrm{~d}, 100 \%$ of mice in both MTD12813 treatment cohorts survived $\geq 28$ days $\left(P \leq 2.2 \times 10^{-6}\right)$ compared to $10 \%$ survival in saline controls. As observed with MTD12813 treatment of Kp-1705 infected mice, peptide treated mice infected with E. coli BAA2340 were healthier than saline controls $24 \mathrm{~h}$ p.i., and appearance and behavior were normal by $96 \mathrm{~h}$.

MTD12813 pharmacokinetics (PK). As noted above, i.p. infection with $K p$-1705 results in rapid dissemination into blood and tissues by $60 \mathrm{~min}$ (Supplemental Data Fig. 1). Since MTD12813 treatment initiated 1 or $3 \mathrm{~h}$ post infection is highly effective (Fig. $2 \mathrm{~b}$ ), it is evident that therapeutic efficacy occurs in the setting of widely disseminated infection. To understand the kinetics of peptide absorption and systemic distribution, single dose PK analysis was performed following administration of $1.25 \mathrm{mg} / \mathrm{kg}$ of MTD12813 in naïve male and female BALB/c mice. MTD12813 was rapidly absorbed from the peritoneum with $\mathrm{T}_{\max }$ of 15 min post injection and a peak plasma concentrations $\left(\mathrm{C}_{\max }\right)$ of $0.251 \pm 0.0798 \mu \mathrm{g} / \mathrm{ml}$ (Supplemental Fig. $2 \mathrm{~b}$ ). Consistent with these results, rapid peritoneal uptake of MTD12813 from the peritoneal fluid (PF) was measured, as the $125 \mu \mathrm{g} / \mathrm{ml}$ peptide infusate was reduced to $\sim 7.5 \mu \mathrm{g} / \mathrm{ml}$ within $2 \mathrm{~min}$ of i.p. administration (Supplemental Fig. 2b). Of note, no bacterial killing was observed in vitro when $\mathrm{Kp}$ - 1705 was incubated in PF containing $7.5 \mu \mathrm{g} / \mathrm{ml}$ peptide (Supplemental Fig. 2c), consistent with an indirect mode of action of MTD12813.

MTD12813 promotes bacterial clearance, phagocytosis, and neutrophil recruitment in Kp-1705 septicemia. Organs from long term survivors (28 days) of MTD12813-treated, Kp-1705 infected mice lacked culturable bacteria (data not shown), demonstrating that survival is associated with bacterial clearance. The effect of MTD12813 on bacterial clearance was evaluated in blood, spleen, and peritoneal lavage fluid (PLF) from mice 4 or $24 \mathrm{~h}$ after infection following a single dose treatment with saline or $1.25 \mathrm{mg} / \mathrm{kg}$ MTD12813 $1 \mathrm{~h}$ p.i. (Fig. 3a). MTD12813 treatment significantly reduced bacterial burden in all three tissues at both 4 and $24 \mathrm{~h}(\mathrm{P}<0.003)$ (Fig. 3a). Within $3 \mathrm{~h}$ (4 h p.i.) of MTD12813 treatment, viable bacteria were reduced by $79.1 \%$, $70.4 \%$, and $99.5 \%$ in blood, spleen, and PLF, respectively, compared to saline treated animals. By $24 \mathrm{~h}$, at which time MTD12813 treated mice showed marked improvements in clinical appearance and activity, bacterial burdens were further reduced by $93.8 \%$ in blood, $94.4 \%$ in spleen homogenates, and $99.8 \%$ in PLF, demonstrating that MTD12813 rapidly promotes bacterial clearance.

To further evaluate the effect of peptide treatment on bacterial clearance, cytospin preparations of PLF of Kp-1705 infected mice were evaluated 2, 4, or 24 h p.i. in MTD12813 and saline treated mice. Compared to saline controls, MTD12813-treated mice showed a marked increase in peritoneal cell associated or phagocytosed bacteria, and few extracellular bacteria were evident (Fig. 3b). Additionally, peptide treatment promoted a significant increase in peritoneal neutrophils $4 \mathrm{~h}$ p.i. (data not shown) which progressed to a threefold increase in PLF neutrophils at $24 \mathrm{~h}(\mathrm{P}=0.0048$; Fig. 3c). The peptide-induced neutrophilic infiltrate was only observed in infected mice, as MTD12813 treatment of sham-infected mice showed no increase in neutrophil numbers $24 \mathrm{~h}$ after peptide delivery (Fig. 3c). In parallel, a transient peripheral blood neutrophilia occurred in infected mice treated with MTD12813 (but not saline) which peaked at ca. $2 \mathrm{~h}$ p.i. (Fig. 3d). By 4 h p.i., blood neutrophil counts in MTD12813-treated mice were not significantly different from those of mice treated with saline (Fig. 3d). Modest, but not statistically significant, elevations in monocytes at $2 \mathrm{~h}$ p.i. were observed in MTD12813 treated mice, while lymphocyte, eosinophil, and basophil levels showed no apparent differences among treatment groups (data not shown). Interestingly, a similar transient neutrophilia was observed in blood collected from naïve BALB/c mice treated with a single i.p. dose of MTD12813 (Fig. 3e).

MTD12813 promotes bacterial phagocytosis. To further analyze the effect of MTD12813 on phagocytic activity, we analyzed the effect of the peptide on phagocytosis of Kp-1705 by mouse RAW 264.7 mac- 
a

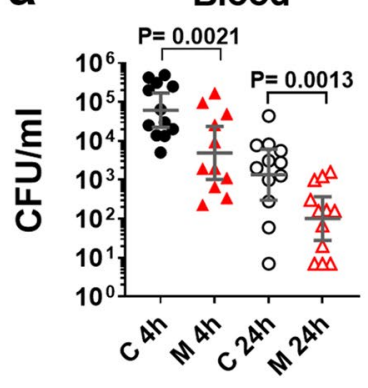

b
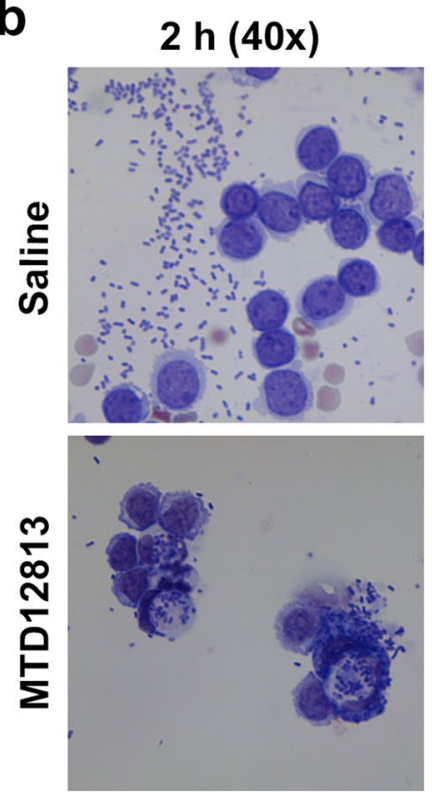

C

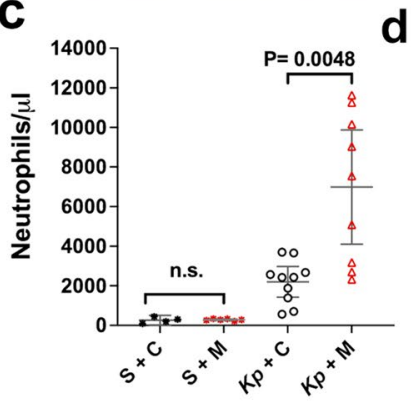

Spleen

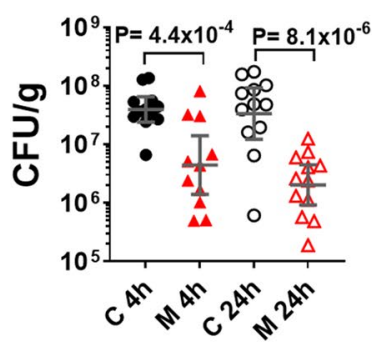

$4 \mathrm{~h}(20 \mathrm{x})$
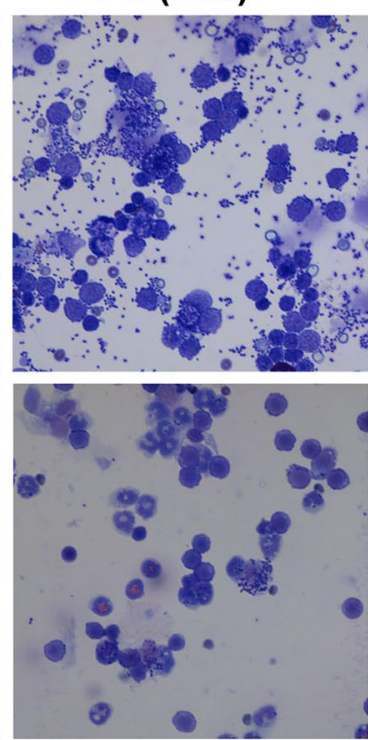

d

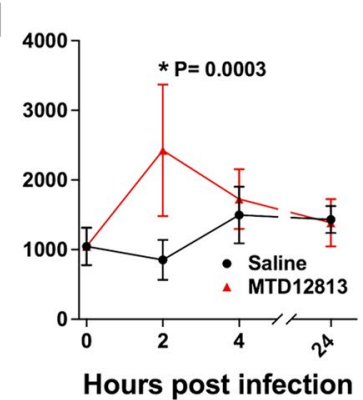

Peritoneal Lavage

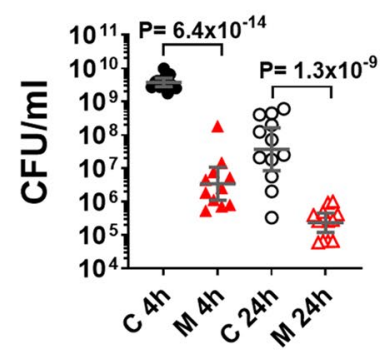

$24 \mathrm{~h}(20 \mathrm{x})$
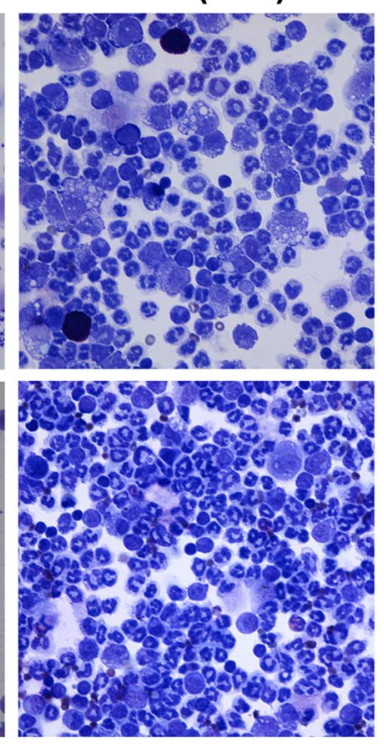

e

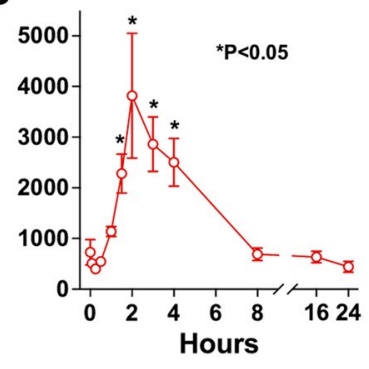

Figure 3. MTD12813 promotes bacterial clearance, neutrophil recruitment and phagocytosis in $K p-1705$ bacteremia. (a-d) BALB/c mice were challenged i.p. with $K p-1705\left(3-5 \times 10^{8} \mathrm{CFU}\right)$ and treated with $1.25 \mathrm{mg} /$ $\mathrm{kg}$ MTD12813 (M) or saline control (C) $1 \mathrm{~h}$ p.i. (a) Mice were euthanized 4 or $24 \mathrm{~h}$ p.i. and bacterial burden determined. Data are geometric means $\pm 95 \%$ CI with P values calculated using Student's t-test. (b) At 2, 4, and $24 \mathrm{~h}$ p.i., peritoneal lavage fluid was collected and cytospin preparations stained with H \& E. (c) Peritoneal neutrophils were collected and counted $24 \mathrm{~h}$ p.i. from sham $(\mathrm{S})$ and $K p-1705(K p)$ infected mice treated $1 \mathrm{~h}$ p.i. with saline (C) or $1.25 \mathrm{mg} / \mathrm{kg}$ MTD12813 (M). (d) Blood neutrophils from infected animals treated $1 \mathrm{~h}$ p.i. were quantified at $\mathrm{t}=0,2,4$ and $24 \mathrm{~h}$, data shown as means $\pm 95 \% \mathrm{CI}(\mathrm{n}=5$ for sham $\mathrm{n}=9-12$ for trx groups), $P$ values determined by Student's t-test with Welch's correction. (e) Naïve BALB/c mice (2M/2F per time point) received $1.25 \mathrm{mg} / \mathrm{kg}$ MTD12813 by a single i.p. injection, and blood neutrophil numbers were determined by $\mathrm{CBC}$ analysis. Graph depicts means \pm SD, $\mathrm{P}$ values determined by Student's t-test comparing each time point to $\mathrm{t}=0$.

rophages. Co-incubation of live Kp-1705 with RAW 264.7 cells with 0-10 $\mu \mathrm{g} / \mathrm{ml}$ MTD12813 showed a concentration dependent inverted-U induction of phagocytosis (Fig. 4a). Maximal phagocytic activity was observed at $0.313 \mu \mathrm{g} / \mathrm{ml}$, which resulted in a 12.6 -fold increase in mean phagocytic index $\left(\mathrm{P}<1 \times 10^{-6}\right.$; Fig. $\left.4 \mathrm{a}\right)$ relative to no peptide controls, and the increase was readily observed microscopically (Fig. 4b). Of note, maximal phagocytic 
a

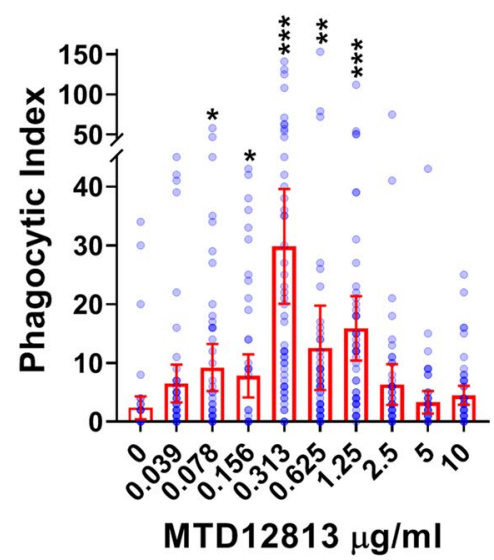

b
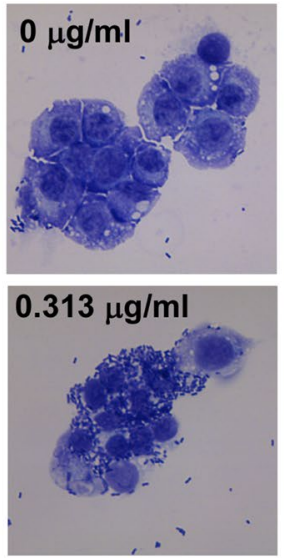
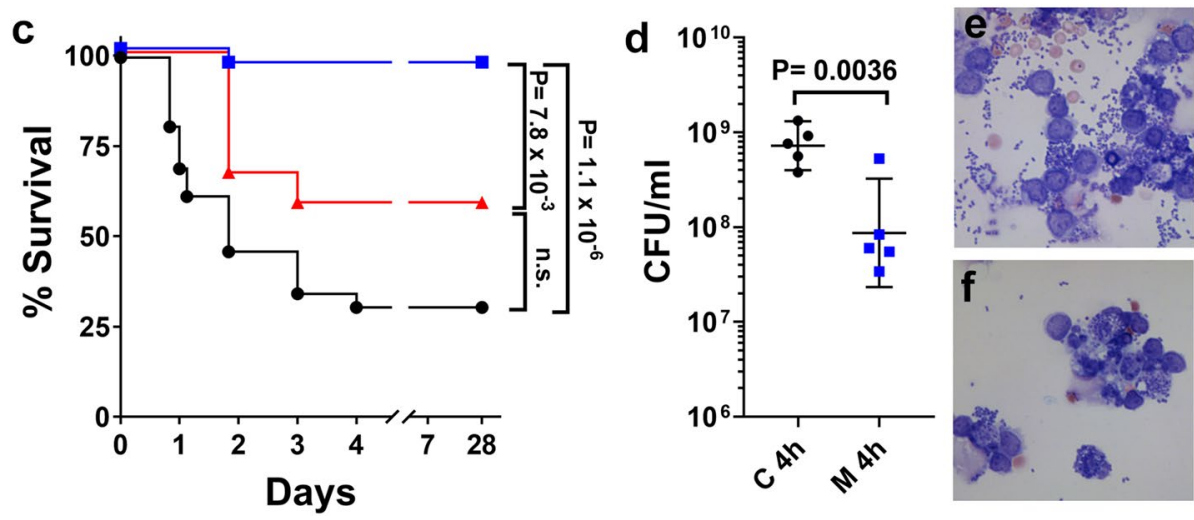

Figure 4. MTD12813 promotes phagocytosis of Kp-1705. (a-b) Phagocytosis by RAW 264.7 macrophages incubated with MTD12813 in the presence of Kp-1705 (50:1 MOI). (a) Cytospins were stained with H\&E and phagocytic index (bacteria per cell) was determined manually. Scatter plots depict means $\pm 95 \%$ CI, P values determined by ANOVA with Uncorrected Fisher's LSD post test, ${ }^{\star} \mathrm{P} \leq 0.05,{ }^{* *} \mathrm{P}<0.01,{ }^{* *} \mathrm{P}<0.0001$. (b) Images comparing effects of 0 and $0.313 \mu \mathrm{g} / \mathrm{ml}$ MTD12813 on phagocytic activity. (c) Mice were challenged i.p. with $K p$ BAA-1705 cells preincubated for $1 \mathrm{~h}$ prior to infection with saline $(\mathbf{O}, \mathrm{n}=26)$ or $1.25 \mu \mathrm{g} / \mathrm{ml}$ MTD12813 $(\boldsymbol{\square}, \mathrm{n}=26)$. A control cohort received saline preincubated bacteria followed immediately by i.p. treatment with $500 \mu \mathrm{l}$ of MTD12813 at $1.25 \mu \mathrm{g} / \mathrm{ml}(\boldsymbol{\Delta}, \mathrm{n}=12)$. Survival of each cohort is shown. Experiment was repeated 4 times, $\mathrm{P}$ values determined by Fisher's exact test. (d) PLF was collected from 5 mice challenged with saline (C) or MTD12813-pretreated $K p$-1705 (as in panel c) that were euthanized 4 h p.i., and bacteria in each sample were quantified by plating (means \pm SD; P values by Student's t-test). $\mathrm{H} \& \mathrm{E}$ stained cytospin preparations from saline (e) and MTD12813-pretreated samples (f).

activity was achieved at peptide levels approximating the plasma $\mathrm{C}_{\max }$ values obtained following i.p. administration of $1.25 \mathrm{mg} / \mathrm{kg}$ MTD12813 (Suppl. Fig. 2).

The phagocytosis-inducing activity of MTD12813 was further analyzed by incubating live Kp-1705 cells with $1.25 \mu \mathrm{g} / \mathrm{ml}$ of MTD12813 (1/5 the MIC under optimal conditions; Table 1) and challenging mice with MTD12813 pre-treated bacteria. Although pre-treatment had no effect on bacterial viability or replication fitness of the organism (Supplemental Fig. 4), mice challenged with the bacteria-peptide mixture were protected (Fig. 4c). Because no statistically significant protection was afforded by i.p. administration of an equal quantity of peptide $(0.5 \mathrm{ml}$ of $1.25 \mu \mathrm{g} / \mathrm{ml})$ immediately following infection, we inferred that preincubation of bacteria with MTD12813 renders them susceptible to host clearance. Also, pre-incubation with MTD12813 markedly increased bacterial killing and phagocytosis in the peritoneal cavity (Fig. 4d-f), consistent with the effect of peptide treatment on phagocytosis and bacterial killing of Kp-1705 infected mice (Fig. 3a,b).

MTD12813 modulates cytokine responses in Kp-1705 induced sepsis. We analyzed the effect of MTD12813 treatment on cytokines associated with host responses to infection that are implicated in the immunopathology of bacteremic sepsis. Multiplex analysis of 32 mouse cytokines was performed on plasma samples collected 2, 4, and $24 \mathrm{~h}$ p.i. from Kp-1705 septicemic mice treated with MTD12813 or saline (Fig. 5 and Supplemental Table 1). Kp-1705 infection induced a rapid and profound elevation of 26 cytokines, some of which increased $>1000$ fold within 2-4 h p.i. (Supplemental Table 1). Plasma levels of six cytokines (IL-2, IL-3, IL-4, IL-7 and VEGF) were not significantly altered by Kp-1705 infection nor were they affected by MTD12813 treatment. 

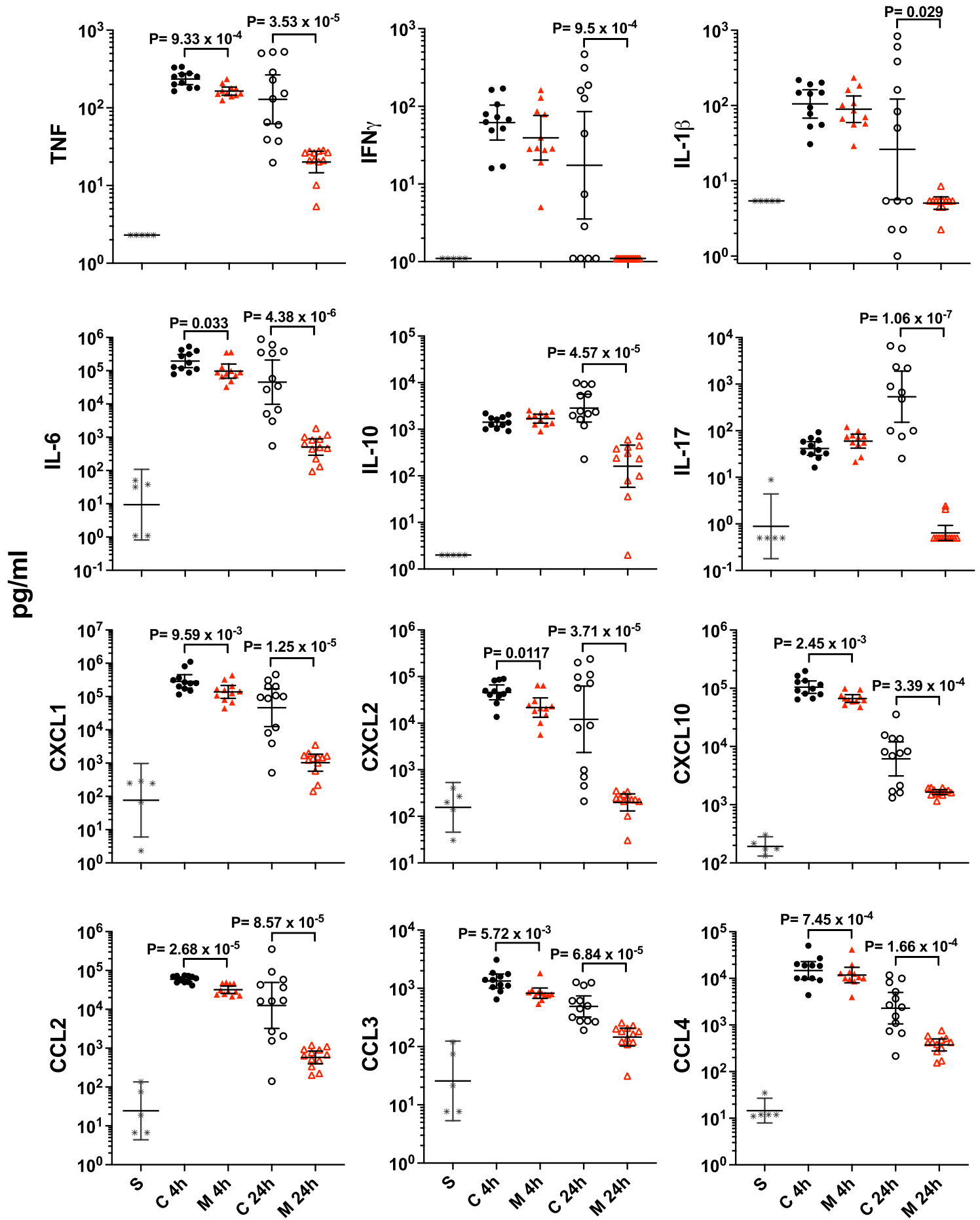

Figure 5. MTD12813 modulation of cytokine responses in Kp-1705 sepsis. Mice were challenged i.p. with Kp-1705 and treated $1 \mathrm{~h}$ later with MTD12813 (1.25 mg/kg i.p.) (M) or saline (C). The sham (S) cohort received bacteria-free suspension buffer at $\mathrm{t}=0$ followed by saline $1 \mathrm{~h}$ later. Mice were euthanized 4 or $24 \mathrm{~h}$ p.i. and plasma samples and cytokines quantified. P values were calculated using ANOVA with Uncorrected Fisher's LSD.

MTD12813 treatment had selective and differential effects on initial early ( 2 and $4 \mathrm{~h}$ p.i.) and later ( $24 \mathrm{~h}$ p.i.) cytokine responses in Kp-1705 infected mice (Fig. 5 and Supplemental Table 1). The earliest ( $2 \mathrm{~h}$ ) effects seen were statistically significant reductions of CCL4 and CXCL2 (Supplemental Table 1). By $4 \mathrm{~h}$ p.i., 7 additional cytokines were significantly reduced, including TNF, IL-6, and CXCL1 (KC) which have major roles in sepsis pathogenesis (Fig. 5). MTD12813 treatment also resulted in significant increases of IL-9 and IL-15 levels at $4 \mathrm{~h}$ p.i. (Supplemental Table 1). 

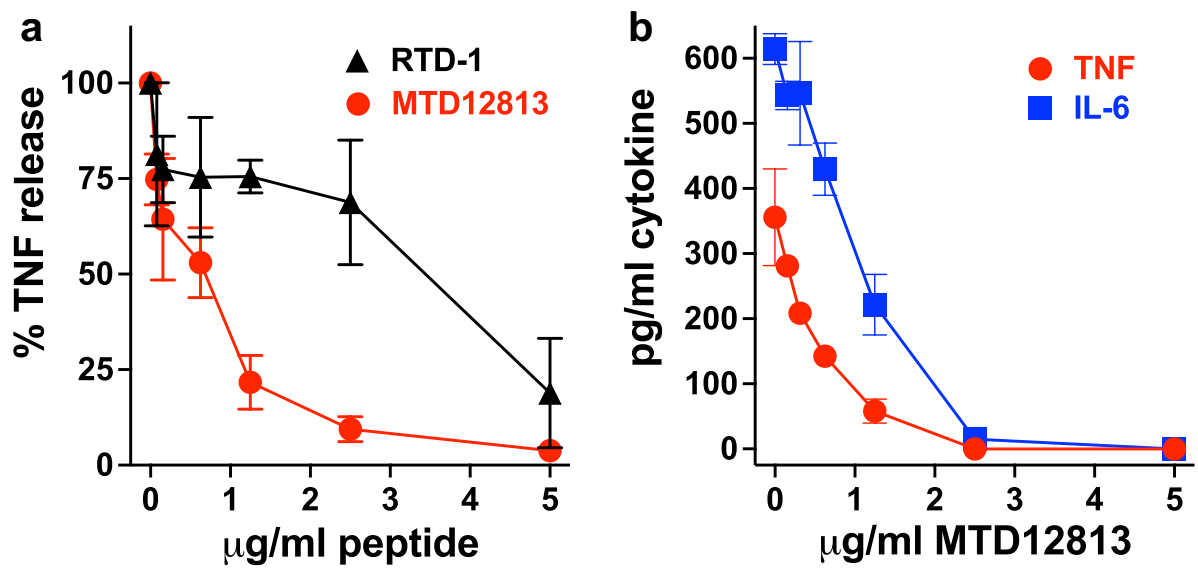

Figure 6. In vitro MTD12813 modulation of cytokine responses. (a) LPS-stimulated RAW 264.7 cells were incubated with MTD12813 $(\mathbf{O})$ or RTD-1 $(\mathbf{\Delta})$ for $2 \mathrm{~h}$ and supernatant TNF quantified by ELISA. (b) Human whole blood was incubated for $4 \mathrm{~h}$ with $1000 \mathrm{CFU} / \mathrm{ml}$ of $\mathrm{Kp}-1705$ with MTD12813, and supernatant TNF (O) and IL-6 (ם) were quantified by ELISA.

Although several early ( 2 or $4 \mathrm{~h}$ ) cytokine responses were selectively regulated by MTD12813 treatment, there was a global reduction in all 26 plasma cytokines affected by $K p-1705$ infection at the $24 \mathrm{~h}$ time point, including those that had been increased initially (IL-9 and IL-15; Fig. 5 and Supplemental Table 1). With the exception of IL-15 $(\mathrm{P}=0.052)$, reductions of cytokine levels were significant compared to saline treated controls (Supplemental Table 1), and levels of 23 cytokines were reduced by $>80 \%$, most notably TNF, $\left(-89.8 \% ; \mathrm{P}=3.52 \times 10^{-5}\right)$, IL-6 $\left(-99.7 \% ; \mathrm{P}=4.38 \times 10^{-6}\right)$, CXCL1 (KC) $\left(-98.8 \%\right.$; $\left.\mathrm{P}=1.25 \times 10^{-5}\right)$, and IL-17 $\left(-100.0 \%\right.$; $\left.=1.06 \times 10^{-7}\right)$ (Fig. 5). Moreover, MTD12813 treatment restored 14 cytokines to sham control levels by $24 \mathrm{~h}$ (Fig. 5, Supplemental Table 1).

The effect of MTD12813 administration on plasma cytokines was also analyzed in uninfected mice that received saline (sham infection controls) followed $1 \mathrm{~h}$ later with a single i.p. dose of $1.25 \mathrm{mg} / \mathrm{kg}$ peptide. At the $4 \mathrm{~h}$ collection point, only three of the 32 mouse cytokines changed significantly relative to sham/saline controls: IL-5, IL-6, and CXCL1 were significantly elevated compared to vehicle treated controls (Supplemental Fig. 3). However, all three cytokines returned to baseline by $24 \mathrm{~h}$.

MTD12813 modulates cytokine responses in vitro. The effects of MTD12813 and RTD-1 on cytokine responses was further analyzed by incubating LPS-stimulated mouse RAW 264.7 macrophages with $0-5 \mu \mathrm{g} / \mathrm{ml}$ MTD12813 or RTD-1. Consistent with previous studies ${ }^{26}$, RTD-1 suppressed the release of soluble TNF from LPS stimulated macrophages dose dependently (Fig. 6a). MTD12813 also inhibited LPS-stimulated TNF release, but $50 \%$ TNF suppression was obtained at ca. fourfold lower concentration than RTD- 1 . To address the possibility that TNF suppression by MTD12813 was the result of LPS neutralization by the peptide, we evaluated the effect of MTD12813 on LPS activity using the limulus amebocyte lysate assay as described previously ${ }^{11}$ (see "Methods"). No LPS inhibition by the peptide was detected at any concentration used in the RAW cell assays (data not shown), indicating the MTD12813 modulates the macrophage inflammatory response to endotoxin. Of note, the LPS concentration used in the RAW cell assays was 50-fold higher than that used to analyze potential inhibition of LPS by MTD12813.

We then tested the effect of MTD12813 on cytokines released by human whole blood incubated with live Kp-1705 cells. As shown in Fig. 6b, MTD12813 concentration-dependently suppressed the release of TNF and IL-6. Peptide alone had no effect on TNF or IL-6 release (data not shown). These results indicate that the effects of MTD12813 in modulating cytokine responses in vivo in mice and in mouse RAW 264.7 macrophages extend to TNF and IL-6 release by human blood leukocytes.

MTD12813 stability. Preliminary studies of MTD12813 indicated that the peptide is exceedingly stable in aqueous media including acidic solutions as low as $\mathrm{pH} 2.0$ (data not shown). To assess peptide stability further, MTD12813 was incubated in either human EDTA-plasma or serum $(90 \% \mathrm{vol} / \mathrm{vol})$ at $37^{\circ} \mathrm{C}$ for $48 \mathrm{~h}$. Reversedphase UPLC analyses showed that $>95 \%$ of the peptide remained intact following incubation in both matrices. In addition, $1.25 \mu \mathrm{g} / \mathrm{ml}$ MTD12813 was incubated with log-phase Kp-1705 or E. coli ATCC-BAA-2340 suspended in $50 \mathrm{mM}$ HEPES at $37^{\circ} \mathrm{C}$ for $24 \mathrm{~h}$. Intact MTD12813 was quantified by LC-MS/MS which showed $72.4 \pm 0.93 \%$ and $81.3 \pm 2.1 \%$ of MTD12813 was found intact post $K p-1705$ and E. coli incubations respectively. These findings demonstrate that MTD12813 is remarkably resistant to bacterial proteases.

\section{Discussion}

MTD12813 is a bioinspired macrocyclic peptide that is structurally related to naturally occurring $\theta$-defensins. RTD-1, the prototype $\theta$-defensin, was identified as a broad-spectrum antimicrobial peptide in vitro ${ }^{8,9}$. Subsequent studies demonstrated that RTD-1 homeostatically regulates inflammation in infectious and non-infectious 
preclinical models ${ }^{11,12,15,17,18,27}$. Mechanisms implicated in the moderation of cytokine-driven inflammation include modulation of NFKB and MAPK pathways ${ }^{13}$, suppression of TNF release via the inhibition of the proTNF sheddase TACE (ADAM17) ${ }^{26}$, and disease resolution and normalization of gene signatures in models of rheumatoid arthritis ${ }^{18,27}$. Also, systemic administration of RTD-1 promoted fungal clearance and long-term survival in mouse models of disseminated candidiasis ${ }^{15}$. RTD-1 efficacy in this model was not the result of a direct antifungal effect of the peptide, since the plasma $C_{\max }$ value was $<1 \%$ of the MIC of the peptide ${ }^{15}$. RTD- 1 treatment was superior to treatment with fluconazole, and antifungal efficacy correlated with transient induction of peripheral blood neutrophilia and normalization of proinflammatory cytokines including TNF, IL-1 $\beta$, IL-17, and IL-6 ${ }^{15}$.

Among a series of minimized $\theta$-defensins, MTD12813 was identified as a promising candidate based on preliminary studies demonstrating its low toxicity in vitro and in vivo, stability in biological matrices, and suppression of TNF release by LPS-stimulated THP-1 macrophages. Here we show that MTD12813 is highly effective in promoting long term survival, bacterial clearance, and moderation of dysregulated systemic inflammation in CRE septicemia.

Both therapeutic and prophylactic single dose administration of MTD12813 significantly enhanced long term survival following challenge with $K p-1705$, an organism that is resistant to carbapenems in vitro and in vivo. Moreover, the peptide was as effective in vivo as colistin and polymyxin B, drugs of last resort that have limited utility as human therapeutics owing to their toxicities ${ }^{28}$. RTD-1 was also effective in $K p-1705$ sepsis, but at approximately tenfold higher concentrations than the effective dose of MTD12813. In addition, MTD12813 promoted long term survival in mice challenged with a CRE strain of E. coli (BAA-2340; Fig. 2d) demonstrating efficacy against the two most common species of CRE pathogens.

Highly efficacious single dose treatment of both CRE pathogens was obtained with administration of MTD12813 at $1.25 \mathrm{mg} / \mathrm{kg}$, a dose level that resulted in plasma $C_{\max }$ of $0.25 \mu \mathrm{g} / \mathrm{ml}$ which is $>400$ times lower than the MIC of MTD12813 against both organisms in the presence of heat-inactivated serum (>100 $\mu \mathrm{g} / \mathrm{ml})$. Moreover, MTD12813-containing peritoneal fluid had no bactericidal activity against $\mathrm{Kp}-1705$. This demonstrates that the antimicrobial effect of MTD12813 is not direct, but rather is mediated by stimulation of host clearance mechanisms, similar to the therapeutic effect of RTD-1 in systemic candidiasis ${ }^{15}$.

In the bacteremia model employed, $K p-1705$ was widely disseminated in blood and solid organs at the time of MTD12813 treatment. This, and the lack of MTD12813 activity in peritoneal fluid, enabled infection and delayed peptide administration by the same route. Peptide treatment induced marked reductions in bacterial burden in blood, peritoneal lavage, and spleen within $4 \mathrm{~h}$ of treatment, and this was accompanied by a marked peptide-induced neutrophilic infiltrate in the peritoneal cavity. Microscopic analysis of PLF from MTD12813 treated infected mice revealed markedly increased phagocytosis of bacteria compared to control. Blood neutrophil levels were also transiently elevated in infected mice treated with MTD12813 as well as in mock-infected controls, suggesting that the peptide stimulates a systemic neutrophilic response. Of note, i.p. administration of MTD12813 induced transient rises in CXCL1, IL-5, and IL-6 in sham treated mice. CXCL1 is a potent neutrophil chemokine which in concert with its receptor CXCR2, plays a key role as one of two cytokine/receptor axes controlling the migration of neutrophils from the bone marrow ${ }^{29}$. Thus, CXCL1 may mediate MTD12813induced transient neutrophilia.

MTD12813-mediated phagocytosis, revealed by cytologic examination of PLF in infected mice, was recapitulated in vitro by co-incubation of Kp-1705 with RAW 264.7 macrophages in the presence of nanomolar concentrations of the peptide, resulting in up to 12 -fold increases in phagocytic index. Consistent with this, preincubation of Kp-1705 with a sub-MIC concentration of MTD12813 promoted phagocytosis in vivo and markedly enhanced mouse survival (Fig. 4c), evidence that MTD12813 has opsonin-like properties. Mice were also protected from $\mathrm{Kp}$-1705 septicemia by a single dose of MTD12813 administered 1 or $3 \mathrm{~h}$ prior to infection, indicating that systemic levels of the peptide are also effective prophylactically. The degree to which this effect is mediated by induction of phagocytosis in extraperitoneal tissues remains to be determined.

Pathogenesis of septicemia results from an imbalance of the host damage-response framework ${ }^{30}$. Challenge with $K$. pneumoniae initiates host innate immune responses which progress through systemic inflammatory response syndrome, evolving to severe sepsis, and finally in lethal septic shock. This detrimental host response is largely driven by dysregulated cytokine signaling which results in uncontrolled inflammation, host-mediated tissue destruction, disseminated intravascular coagulation, and multiple organ failure ${ }^{25,31,32}$. Modulation of cytokine responses in MTD12813 treated mice was associated with suppression of otherwise immunopathologic cytokine release without inducing an immunocompromised state. Moreover, MTD12813 treatment significantly enhanced the recruitment of neutrophils to the peritoneal cavity, an innate immune response which is often accompanied by inflammatory tissue damage. However, MTD12813-induced neutrophil recruitment was accompanied by increased phagocytosis, bacterial clearance, and homeostatic resolution of plasma cytokines.

Although mouse models of bacteremic sepsis are distinct from human sepsis syndromes, they are a common starting point for identification of infectious disease drug candidates ${ }^{33-36}$. To address the potential of MTD12813 as a human therapeutic, we analyzed the immunomodulatory activity of the peptide on TNF and IL-6 expression by bacteria-stimulated human blood leukocytes. The peptide suppressed release of both cytokines in a concentration dependent manner. Other experiments showed that MTD12813 is remarkably stable in plasma and when incubated for $24 \mathrm{~h}$ with live CRE isolates, suggesting that this macrocyclic peptide is an attractive candidate for further preclinical development. Additional studies showed that i.p. administration of MTD12813 is well tolerated in $\mathrm{BALB} / \mathrm{c}$ mice at doses more than 100 -fold higher than the $0.5 \mathrm{mg} / \mathrm{kg}$ efficacious dose (data not shown).

In recent years there has been a dramatic increase in the development and approval of peptide drugs ${ }^{37,38}$. However, this has not been the case for clinical development of direct acting antimicrobial peptides (AMPs) ${ }^{39,40}$. Historic challenges in clinical development of AMP-based drugs have been due to toxicity, poor activity in biological matrices, or poor bioavailability/pharmacokinetics ${ }^{40}$. More recent efforts have focused on the development 
of anti-infective peptides that have host directed modes of action. Examples include innate defense regulator (IDR) - 1018 and CD28 mimetic AB103 $\left(\right.$ Reltecimod $\left.^{\mathrm{Tn}}\right)$. IDR-1018 is an immunomodulatory dodecapeptide amide that was bioinspired by the bovine cathelicidin Bac2a. IDR-1018 was effective in treatment of systemic candidiasis in mice, with efficacy mediated by modulation of proinflammatory cytokines ${ }^{41}$. AB103 $\left(\right.$ Reltecimod $\left.^{\mathrm{Tx}}\right)$ is a CD28 mimetic that disrupts T-cell CD28 stimulatory pathways by blocking the binding of exotoxin superantigens to CD28 and preventing downstream overactivation of T-cell driven proinflammatory cytokine responses ${ }^{42,43}$. The potential of immunomodulatory peptides was illustrated after a Phase III human trial of AB103 was completed for treatment of necrotizing soft-tissue infections ${ }^{44,45}$.

Here, we report the first use of a $\theta$-defensin-inspired macrocyclic peptide for treatment of Gram negative bacterial infections. Like RTD-1, the mechanism of action of MTD12813 is host directed, and therefore, less likely to select for drug resistance than conventional antibiotics ${ }^{46}$. Moreover, the stability and pharmacologic properties of MTD12813 suggests that it represents a promising new class of immunomodulating anti-infectives much needed to address the worldwide crisis resulting from antimicrobial resistance.

\section{Materials and methods}

Ethics. All methods were performed in accordance with relevant federal, state, and institutional guidelines. All animal studies were performed in compliance with ARRIVE guidelines 2.0. Animal use protocols were approved by The University of Southern California (USC) Institutional Animal Care and Use Committee (IACUC), Protocol \#20538. Blood was obtained from healthy adult volunteers according to approved USC Institutional Review Board (IRB) Protocol HS-09-00280.

Peptides and antibiotics. The hydrochloride salts of MTD12813 and RTD-1 (>95\%) were produced by solid phase peptide synthesis as described ${ }^{10,14}$. Imipenem (I0160), meropenem (M2574), ceftazidime (A6987), colistin (C4461), and polymyxin B (P0972) were purchased from Sigma-Aldrich (St. Louis, MO). Stock solutions of MTD12813, RTD-1, and antibacterial drugs were prepared as concentrated stocks in sterile water. For animal injection, peptides and antibacterial drugs were diluted to the indicated concentrations in sterile normal saline.

Bacterial strains. Bacterial strains were obtained from American Type Culture Collection. K. pneumoniae strains included BAA-1705 ( $b l a_{\mathrm{KPC}-2}$, hypermucoid), BAA-2146 (bla $\left.a_{\mathrm{NDM}-1}\right), \mathrm{BAA}-700603$ (SHV-18, extended spectrum $\beta$-lactamase, ESBL), and BAA-1706 (non-CRE reference strain). E. coli strains included BAA-2340 $\left(b l a_{\mathrm{KPC}-2}\right), \mathrm{BAA}-2471\left(b l a_{\mathrm{NDM}-1}\right)$, and ML35 (non-CRE reference strain).

Antibacterial assays. Minimum inhibitory concentration (MIC) assays were performed $\pm 50 \%$ heat-inactivated mouse serum using Clinical and Laboratory Standards Institute (CLSI; document M07-A9) protocols. Bacteria $\left(5 \times 10^{5} \mathrm{CFU} / \mathrm{ml}\right)$ were incubated with antibiotics or peptide for $20 \mathrm{~h}$ at $37^{\circ} \mathrm{C}$, and bacterial growth was determined by $\mathrm{A}_{620}$ using a SpectraMax M5e plate reader. MIC was the lowest agent concentration that completely inhibited growth as determined by $\mathrm{A}_{620}$ absorbance.

K. pneumoniae and $\boldsymbol{E}$. coli bacteremia. BALB/c mice (Jackson Laboratories) 8-10 weeks of age were acclimated (3-5 to a cage for at least 5 days prior to infection) in a thermostatically controlled room with $12 \mathrm{~h}$ light/dark cycle. Cryopreserved K. pneumoniae ${ }^{47}$ cells were thawed and adjusted to a density of $6-10 \times 10^{8} \mathrm{CFU} /$ $\mathrm{ml}$, confirmed by plating on trypticase soy agar (TSA) plates. E. coli BAA-2340 was grown to log-phase in trypticase soy broth, pelleted, washed with PBS, and resuspended in PBS at $0.5-1 \times 10^{9} \mathrm{CFU} / \mathrm{ml}$. Mice were infected by i.p. injection of $2-5 \times 10^{8} \mathrm{CFU}$ of $\mathrm{Kp}-1705$ or $3-6 \times 10^{7} \mathrm{CFU}$ of $E$. coli BAA-2340 using a $28 \mathrm{~g}$ needle in a volume of $0.5 \mathrm{ml}$. Post-infection, mice were observed three times a day for at least 4 days and then daily for 28 days. Mice were euthanized when they became moribund. All experiments used both male and female mice and were repeated at least twice.

Bacterial burden determination. Blood, peritoneal lavage fluid, and spleen homogenates were obtained from mice following by $\mathrm{CO}_{2}$ euthanasia. Citrate-anti-coagulated blood was collected by aseptic cardiac puncture. Peritoneal lavage was performed by injecting $3 \mathrm{ml}$ of PBS into the peritoneal cavity, massaging the abdomen, and then collecting fluid aseptically through a minor incision in the abdominal wall. Spleen was surgically removed and homogenized in sterile PBS using Polytron PT10-35 homogenizer. Samples were serially diluted and plated in triplicate on TSA plates, incubated overnight at $37^{\circ} \mathrm{C}$ and colonies counted.

Hematology and cytokine analyses. EDTA-anticoagulated blood was collected aseptically by terminal cardiac puncture and analyzed for complete blood cell count using an Element HT5 hematology analyzer (Heska). Blood plasma and clarified peritoneal lavage were prepared by two-step centrifugation described previousl $^{24}$. Plasma cytokine levels were quantified using a mouse-specific MILLIPLEX MAP kit (Millipore Cat\# MCYTMAG-70K) as described ${ }^{11}$.

MTD12813 pharmacokinetics. Single dose PK of MTD12813 was evaluated by quantifying plasma peptide concentrations following $1.25 \mathrm{mg} / \mathrm{kg}$ injections administered i.p. to $2 \mathrm{M} / 2 \mathrm{~F}$ BALB/c mice. EDTA plasma was prepared from blood collected aseptically by terminal cardiac puncture. MTD12813 plasma concentrations were determined by reverse-phase liquid chromatography (XBridge phenyl $3.5 \mu \mathrm{m}$ column, Waters) on an Acquity H-Class UPLC (Waters) with tandem electrospray mass spectroscopy on a Xevo TQ-S running Mass- 
Lynx V4.1 (Waters). Quantitative mass spectroscopy was performed by multiple-reaction monitoring transition $394.04>519.35$, with area under the curve determined by TargetLynx (Waters).

Cell culture. Mouse RAW 264.7 macrophages (RAW cells; ATCC, TIB-71) were grown in Dulbecco's Modified Eagle Medium (DMEM) with 10\% heat-inactivated fetal bovine serum (HI-FBS) with $100 \mathrm{U} / \mathrm{ml}$ penicillin/ streptomycin, and suspended to $2-3 \times 10^{6} \mathrm{cells} / \mathrm{ml}$ in fresh media before use.

Phagocytosis assay. Kp-1705 was grown overnight, harvested by centrifugation, washed twice, resuspended in Hank's Balanced Salt Solution (HBSS), and adjusted to a density of $2.5 \times 10^{8} \mathrm{CFU} / \mathrm{ml}$. Bacteria were pre-incubated with varied concentrations of MTD12813 at room temperature for $30 \mathrm{~min}$, and incubated (MOI 50:1) with RAW cells $\left(2.5 \times 10^{6} \mathrm{cell} / \mathrm{ml}\right)$ with orbital shaking at $37^{\circ} \mathrm{C}$ for $30 \mathrm{~min}$. Cytospin preparations of $100 \mu \mathrm{l}$ $\left(2.5 \times 10^{5} \mathrm{RAW}\right.$ cells/slide) samples were then prepared, fixed with methanol, and stained with hematoxylin and eosin $(\mathrm{H} \& \mathrm{E})$. Slides were viewed at $100 \times$ and 50 RAW cells selected from random fields were manually counted for number of cell associated bacteria. All samples were run in duplicate and experiments performed twice. RAW cell viability post incubation was determined in parallel using trypan blue stain and SYTOX Green nucleic acid viability stain, both of which demonstrated cell viability of $>95 \%$.

LPS stimulation of RAW cells. RAW cells were seeded into 48 -well tissue culture plates at $1-1.5 \times 10^{5}$ cells/well and allowed to adhere overnight. Cells were washed twice and suspended in DMEM with $1 \%$ FBS with $0-5 \mu \mathrm{g} / \mathrm{ml}$ of MTD12813 immediately followed by addition of $5 \mathrm{ng} / \mathrm{ml}(25 \mathrm{EU} / \mathrm{ml})$ of E. coli 0111:B4 LPS (Sigma L4391). Plates were incubated for $2 \mathrm{~h}$ at $37^{\circ} \mathrm{C}$ in $5 \% \mathrm{CO}_{2}$. Well contents were removed, clarified by centrifugation, and supernatants frozen at $-80^{\circ} \mathrm{C}$. Supernatant TNF was quantified by mouse TNF ELISA (Invitrogen, Cat \#BMS607-3).

LPS neutralization analysis. A limulus amebocyte lysate endotoxin detection assay (Pierce A39553) protocol was employed by preincubating $0.5 \mathrm{EU} / \mathrm{ml}$ of LPS with either MTD12813, RTD-1, or colistin $(0.078-5 \mu \mathrm{g} /$ $\mathrm{ml}$ ) in $\mathrm{H}_{2} \mathrm{O}$ at $37^{\circ} \mathrm{C}$ for 30 min followed by quantifying free LPS per manufacturer's instructions. All samples were compared to a LPS standard curve to determine the degree of LPS neutralization.

Bacterial stimulation of human blood. Log-phase $K p-1750$ grown in TSB were pelleted, washed twice in PBS, and suspended to $1 \times 10^{5} \mathrm{CFU} / \mathrm{ml}$ in RPMI-1640. EDTA-anticoagulated blood collected from a healthy adult human donor was incubated at a final dilution of 1:10 in RPMI-1640 with $1000 \mathrm{CFU} / \mathrm{ml}$ of $\mathrm{Kp}-1705$ and varied concentrations of MTD 12813 for $4 \mathrm{~h} 37^{\circ} \mathrm{C}$ in $5 \% \mathrm{CO}_{2}$ with gentle rocking. Incubation supernatants were frozen at $-80^{\circ} \mathrm{C}$. TNF and IL- 6 were quantified by ELISA (Invitrogen KHC3011, KHC0061).

Peptide stability analysis. MTD12813 (final concentration of $100 \mu \mathrm{g} / \mathrm{ml}$ ) was added to either $90 \%$ human EDTA plasma or $90 \%$ human serum and incubated at $37^{\circ} \mathrm{C}$ for $48 \mathrm{~h}$. Samples were processed by addition of $10 \%$ HOAc and 5\% ACN (final concentrations) at time 0 and $48 \mathrm{~h}$, and MTD12813 was quantified by $\mathrm{C}_{18}$ RP-HLPC on an Acquity H-Class UPLC with an analytical PDA detector using Empower 3 software (Waters). All samples were performed with technical replicates and analyzed by UPLC in duplicate and the experiment repeated once. In separate experiments, MTD12813 $\left(1.25 \mu \mathrm{g} / \mathrm{ml}\right.$ final) was incubated with log phase $\mathrm{Kp}-1705\left(5 \times 10^{7} \mathrm{CFU} / \mathrm{ml}\right)$ in $50 \mathrm{mM}$ HEPES $\mathrm{pH}$ 7.4. A time $0 \mathrm{~h}$ sample was collected, and the remaining suspension incubated at $37^{\circ} \mathrm{C}$ for $24 \mathrm{~h}$. Samples were processed by addition of $5 \%$ formic acid $/ 5 \%$ acetonitrile, vortexed, and clarified at $22,000 \times g$ for $10 \mathrm{~min}$. Supernatant MTD12813 was then quantified by LC-MS/MS as described in PK section above. All samples were performed with technical replicates and analyzed by LC-MS/MS in duplicate.

In vivo phagocytosis and peritoneal bioburden determination. Cryopreserved Kp-1705 was suspended in PBS to a density of ca. $1 \times 10^{9} \mathrm{CFU} / \mathrm{ml}$, and incubated with saline or $1.25 \mu \mathrm{g} / \mathrm{ml}$ MTD12813 at room temperature for $1 \mathrm{~h}$. Mice $(\mathrm{n}=26)$ were then infected i.p. with $500 \mu \mathrm{l}$ of saline- or MTD12813- pretreated Kp1705 , and a third cohort $(n=12)$ received $500 \mu \mathrm{l}$ i.p. of $1.25 \mu \mathrm{g} / \mathrm{ml}$ MTD12813 immediately following infection with saline treated $K p$-1705. Five mice from each cohort were euthanized $4 \mathrm{~h}$ p.i., and peritoneal lavage was collected for bacterial burden determination and cytospin preparation. In vitro antibacterial activity of MTD12813 $(1.25 \mu \mathrm{g} / \mathrm{ml})$-treated cells $\left(1 \mathrm{~h} ; 37^{\circ} \mathrm{C}\right)$ was determined by plating saline or peptide treated cells on TSA plates. Growth kinetics of saline and MTD12813-treated cells was determined by diluting samples from the $1 \mathrm{~h}$ incubation mixtures 1:40 into TSB and monitoring growth $(620 \mathrm{~nm})$ for $5.5 \mathrm{~h}$ at $37^{\circ} \mathrm{C}$. Antibacterial activity of MTD12813 in PF was determined by i.p. injection of naïve male BALB/c mice ( $\mathrm{n}=5$ per group) with $1.25 \mathrm{mg} / \mathrm{kg}$ of MTD12813 or saline i.p. (10 ml/kg). Mice were euthanized $1 \mathrm{~h}$ after i.p. injection and peritoneal fluid was harvested aseptically using a micropipette introduced into a surgical incision in the abdominal wall. Peritoneal fluid was clarified by centrifugation at $1200 \times g$ and an aliquot used to quantify MTD12813 by LC-MS/ MS, as described above. Antimicrobial activity was determined by incubating PF (9:1 vol/vol) with Kp-1705 at a final density of $3 \times 10^{7} \mathrm{CFU} / \mathrm{ml}$. Samples were incubated at $37^{\circ} \mathrm{C}$ for $1 \mathrm{~h}$, serially diluted, and plated on TSB to determine bacterial viability.

Statistical analyses. All statistical analyses were performed using GraphPad Prism Version 8.2.1. Endpoint survival data were compared using Fisher's exact test. P values of $\leq 0.05$ were defined as significant. Statistics analyzing bacterial burdens and cytokine responses first confirmed lognormal distribution by AndersonDarling test. Values were then log-transformed and analyzed by one-way ANOVA with an Uncorrected Fisher's 
Least Significant Difference (LSD) post-test. Student's t-tests were performed using a two-tail analysis. All other statistical analyses are described in figure legends.

\section{Data availability}

The datasets generated during and/or analyzed during the current study are available from the 350 corresponding author on reasonable request.

Received: 22 September 2021; Accepted: 18 November 2021

Published online: 06 December 2021

\section{References}

1. Centers for Disease Control and Prevention. Antibiotic Resistance Threats in the United States. (US Department of Health and Human Services CDC, 2013).

2. Oneill, J. Tackling Drug-Resistant Infections Globally: Final Report and Recommendations (Wellcome Trust, 2016).

3. Papp-Wallace, K. M., Endimiani, A., Taracila, M. A. \& Bonomo, R. A. Carbapenems: Past, present, and future. Antimicrob. Agents Chemother. 55, 4943-4960. https://doi.org/10.1128/AAC.00296-11 (2011).

4. Winkler, M. L. et al. Unexpected challenges in treating multidrug-resistant Gram-negative bacteria: Resistance to ceftazidimeavibactam in archived isolates of Pseudomonas aeruginosa. Antimicrob. Agents Chemother. 59, 1020-1029. https://doi.org/10.1128/ AAC.04238-14 (2015).

5. Poirel, L., Pitout, J. D. \& Nordmann, P. Carbapenemases: Molecular diversity and clinical consequences. Future Microbiol. 2, 501-512. https://doi.org/10.2217/17460913.2.5.501 (2007).

6. Pitout, J. D., Nordmann, P. \& Poirel, L. Carbapenemase-producing klebsiella pneumoniae, a key pathogen set for global nosocomial dominance. Antimicrob. Agents Chemother. 59, 5873-5884. https://doi.org/10.1128/AAC.01019-15 (2015).

7. Munoz-Price, L. S. et al. Clinical epidemiology of the global expansion of Klebsiella pneumoniae carbapenemases. Lancet Infect. Dis. 13, 785-796. https://doi.org/10.1016/S1473-3099(13)70190-7 (2013).

8. Tran, D. et al. Homodimeric theta-defensins from rhesus macaque leukocytes: Isolation, synthesis, antimicrobial activities, and bacterial binding properties of the cyclic peptides. J. Biol. Chem. 277, 3079-3084. https://doi.org/10.1074/jbc.M109117200 (2002).

9. Tongaonkar, P. et al. Rhesus macaque \{theta\}-defensin isoforms: Expression, antimicrobial activities, and demonstration of a prominent role in neutrophil granule microbicidal activities. J. Leukoc. Biol. 89, 283-290. https://doi.org/10.1189/jlb.0910535 (2011).

10. Garcia, A. E., Osapay, G., Tran, P. A., Yuan, J. \& Selsted, M. E. Isolation, synthesis, and antimicrobial activities of naturally occurring theta-defensin isoforms from baboon leukocytes. Infect. Immunol. 76, 5883-5891. https://doi.org/10.1128/IAI.01100-08 (2008).

11. Schaal, J. B. et al. Rhesus macaque theta defensins suppress inflammatory cytokines and enhance survival in mouse models of bacteremic sepsis. PLoS ONE 7, e51337. https://doi.org/10.1371/journal.pone.0051337 (2012).

12. Bensman, T. J. et al. Efficacy of rhesus theta-defensin-1 in experimental models of pseudomonas aeruginosa lung infection and inflammation. Antimicrob. Agents Chemother. https://doi.org/10.1128/aac.00154-17 (2017).

13. Tongaonkar, P. et al. Rhesus macaque theta-defensin RTD-1 inhibits proinflammatory cytokine secretion and gene expression by inhibiting the activation of NF-kappaB and MAPK pathways. J. Leukoc. Biol. 98, 1061-1070. https://doi.org/10.1189/jlb.3A0315102R (2015).

14. Tang, Y. Q. et al. A cyclic antimicrobial peptide produced in primate leukocytes by the ligation of two truncated alpha-defensins. Science 286, 498-502 (1999).

15. Basso, V. et al. Rhesus theta defensin 1 promotes long term survival in systemic candidiasis by host directed mechanisms. Sci. Rep. 9, 16905. https://doi.org/10.1038/s41598-019-53402-z (2019).

16. Wohlford-Lenane, C. L. et al. Rhesus theta-defensin prevents death in a mouse model of severe acute respiratory syndrome coronavirus pulmonary disease. J. Virol. 83, 11385-11390. https://doi.org/10.1128/JVI.01363-09 (2009).

17. Jayne, J. G. et al. Rhesus theta-defensin-1 attenuates endotoxin-induced acute lung injury by inhibiting proinflammatory cytokines and neutrophil recruitment. Am. J. Respir. Cell Mol. Biol. 58, 310-319. https://doi.org/10.1165/rcmb.2016-0428OC (2018).

18. Schaal, J. B. et al. Suppression and resolution of autoimmune arthritis by rhesus theta-defensin-1, an immunomodulatory macrocyclic peptide. PLoS ONE 12, e0187868. https://doi.org/10.1371/journal.pone.0187868 (2017).

19. Lehrer, R. I. \& Lu, W. Alpha-defensins in human innate immunity. Immunol. Rev. 245, 84-112. https://doi.org/10.1111/j.1600-065X. 2011.01082.x (2012).

20. Haudek, S. B. et al. Lipopolysaccharide dose response in baboons. Shock 20, 431-436. https://doi.org/10.1097/01.shk.0000090843. 66556.74 (2003).

21. Reichgott, M. J., Melmon, K. L., Forsyth, R. P. \& Greineder, D. Cardiovascular and metabolic effects of whole or fractionated gram-negative bacterial endotoxin in the unanesthetized Rhesus monkey. Circ. Res. 33, 346-352 (1973).

22. Wessels, B. C. et al. Plasma endotoxin concentration in healthy primates and during E. coli-induced shock. Crit. Care Med. 16, 601-605 (1988).

23. Lehrer, R. I., Cole, A. M. \& Selsted, M. E. theta-Defensins: Cyclic peptides with endless potential. J. Biol. Chem. 287, 27014-27019. https://doi.org/10.1074/jbc.R112.346098 (2012).

24. Schaal, J. B. et al. Macrocyclic theta-defensins suppress tumor necrosis factor-alpha (TNF-alpha) shedding by inhibition of TNFalpha-converting enzyme. J. Biol. Chem. 293, 2725-2734. https://doi.org/10.1074/jbc.RA117.000793 (2018).

25. Shrum, B. et al. A robust scoring system to evaluate sepsis severity in an animal model. BMC Res. Notes 7, 233. https://doi.org/10. 1186/1756-0500-7-233 (2014).

26. Schaal, J. B. et al. Macrocyclic $\theta$-defensins suppress tumor necrosis factor- $\alpha$ (TNF- $\alpha$ ) shedding by inhibition of TNF- $\alpha$-converting enzyme. J. Biol. Chem. 293, 2725-2734. https://doi.org/10.1074/jbc.RA117.000793 (2018).

27. Tongaonkar, P. et al. RTD-1 therapeutically normalizes synovial gene signatures in rat autoimmune arthritis and suppresses proinflammatory mediators in RA synovial fibroblasts. Physiol. Genom. 51, 657-667. https://doi.org/10.1152/physiolgenomics.00066. 2019 (2019).

28. Tsuji, B. T. et al. International Consensus Guidelines for the Optimal Use of the Polymyxins: Endorsed by the American College of Clinical Pharmacy (ACCP), European Society of Clinical Microbiology and Infectious Diseases (ESCMID), Infectious Diseases Society of America (IDSA), International Society for Anti-infective Pharmacology (ISAP), Society of Critical Care Medicine (SCCM), and Society of Infectious Diseases Pharmacists (SIDP). Pharmacotherapy 39, 10-39. https://doi.org/10.1002/phar.2209 (2019).

29. Lerman, Y. V. \& Kim, M. Neutrophil migration under normal and sepsis conditions. Cardiovasc. Hematol. Disord. Drug Targets 15, 19-28. https://doi.org/10.2174/1871529x15666150108113236 (2015).

30. Casadevall, A. \& Pirofski, L. A. The damage-response framework of microbial pathogenesis. Nat. Rev. Microbiol. 1, 17-24. https:// doi.org/10.1038/nrmicro732 (2003). 
31. Buras, J. A., Holzmann, B. \& Sitkovsky, M. Animal models of sepsis: Setting the stage. Nat. Rev. Drug Discov. 4, 854-865. https:// doi.org/10.1038/nrd1854 (2005).

32. Doi, K., Leelahavanichkul, A., Yuen, P. S. \& Star, R. A. Animal models of sepsis and sepsis-induced kidney injury. J. Clin. Invest. 119, 2868-2878. https://doi.org/10.1172/JCI39421 (2009).

33. Murando, F., Peloso, A. \& Cobianchi, L. Experimental abdominal sepsis: Sticking to an awkward but still useful translational model. Mediators Inflamm. 2019, 8971036. https://doi.org/10.1155/2019/8971036 (2019).

34. Zhao, M., Lepak, A. J. \& Andes, D. R. Animal models in the pharmacokinetic/pharmacodynamic evaluation of antimicrobial agents. Bioorg. Med. Chem. 24, 6390-6400. https://doi.org/10.1016/j.bmc.2016.11.008 (2016).

35. Lewis, A. J., Seymour, C. W. \& Rosengart, M. R. Current murine models of sepsis. Surg. Infect. (Larchmt.) 17, 385-393. https://doi. org/10.1089/sur.2016.021 (2016).

36. Poli-de-Figueiredo, L. F., Garrido, A. G., Nakagawa, N. \& Sannomiya, P. Experimental models of sepsis and their clinical relevance. Shock 30(Suppl 1), 53-59. https://doi.org/10.1097/SHK.0b013e318181a343 (2008).

37. Lau, J. L. \& Dunn, M. K. Therapeutic peptides: Historical perspectives, current development trends, and future directions. Bioorg. Med. Chem. 26, 2700-2707. https://doi.org/10.1016/j.bmc.2017.06.052 (2018).

38. Lee, A. C., Harris, J. L., Khanna, K. K. \& Hong, J. H. A comprehensive review on current advances in peptide drug development and design. Int. J. Mol. Sci. https://doi.org/10.3390/ijms20102383 (2019).

39. Chen, C. H. \& Lu, T. K. Development and challenges of antimicrobial peptides for therapeutic applications. Antibiotics (Basel). https://doi.org/10.3390/antibiotics9010024 (2020).

40. Mookherjee, N., Anderson, M. A., Haagsman, H. P. \& Davidson, D. J. Antimicrobial host defence peptides: Functions and clinical potential. Nat. Rev. Drug Discov. 19, 311-332. https://doi.org/10.1038/s41573-019-0058-8 (2020).

41. Freitas, C. G. et al. An immunomodulatory peptide confers protection in an experimental Candidemia Murine model. Antimicrob. Agents Chemother. https://doi.org/10.1128/AAC.02518-16 (2017).

42. Ramachandran, G. et al. CD28 homodimer interface mimetic peptide acts as a preventive and therapeutic agent in models of severe bacterial sepsis and gram-negative bacterial peritonitis. J. Infect. Dis. 211, 995-1003. https://doi.org/10.1093/infdis/jiu556 (2015).

43. Ramachandran, G. et al. A peptide antagonist of $\mathrm{CD} 28$ signaling attenuates toxic shock and necrotizing soft-tissue infection induced by Streptococcus pyogenes. J. Infect. Dis. 207, 1869-1877. https://doi.org/10.1093/infdis/jit104 (2013).

44. Bulger, E. M. et al. Validation of a clinical trial composite endpoint for patients with necrotizing soft tissue infections. J. Trauma Acute Care Surg. 83, 622-627. https://doi.org/10.1097/TA.0000000000001564 (2017).

45. Bulger, E. M. et al. A novel drug for treatment of necrotizing soft-tissue infections: A randomized clinical trial. JAMA Surg. 149, 528-536. https://doi.org/10.1001/jamasurg.2013.4841 (2014).

46. Chiang, C. Y. et al. Mitigating the impact of antibacterial drug resistance through host-directed therapies: Current progress, outlook, and challenges. MBio https://doi.org/10.1128/mBio.01932-17 (2018).

47. Nielsen, T. B., Bruhn, K. W., Pantapalangkoor, P., Junus, J. L. \& Spellberg, B. Cryopreservation of virulent Acinetobacter baumannii to reduce variability of in vivo studies. BMC Microbiol. 15, 252. https://doi.org/10.1186/s12866-015-0580-8 (2015).

\section{Acknowledgements}

This work was supported by Grants from National Institute of Allergy and Infectious Diseases (RO1 AI22931, R01 AI125141), National Institute of Dental and Craniofacial Research Grant (R01DE021341), the Southern California Clinical and Translational Science Institute (UL1 TR000130), and National Cancer Institute (P30 CA014089).

\section{Author contributions}

J.B.S., D.Q.T., A.J.O. and M.E.S. conceived and designed the experiments. J.B.S., Y.E., P.A.T., C.H., A.C., K.P., and K.T., carried out the experiments. J.B.S. contributed to the data analysis. J.B.S., D.Q.T., A.J.O., and M.E.S. contributed to the interpretation of the results. J.B.S. and M.E.S. wrote the main manuscript text. J.B.S. prepared figures and tables. All authors reviewed the manuscript.

\section{Competing interests}

MES is co-founder and Chief Scientific Officer of Oryn Therapeutics, LLC (Oryn). He is an equity holder but receives no income from Oryn. DQT is scientific director of Oryn and is an equity holder. AJO is an equity holder in Oryn but receives no income. Oryn has licensed technology described in this publication from the University of Southern California and the relationship between Oryn and USC is disclosed to and approved by all parties. All other authors declare no competing interests.

\section{Additional information}

Supplementary Information The online version contains supplementary material available at https://doi.org/ 10.1038/s41598-021-02619-y.

Correspondence and requests for materials should be addressed to J.B.S.

Reprints and permissions information is available at www.nature.com/reprints.

Publisher's note Springer Nature remains neutral with regard to jurisdictional claims in published maps and institutional affiliations.

(c) (i) Open Access This article is licensed under a Creative Commons Attribution 4.0 International License, which permits use, sharing, adaptation, distribution and reproduction in any medium or format, as long as you give appropriate credit to the original author(s) and the source, provide a link to the Creative Commons licence, and indicate if changes were made. The images or other third party material in this article are included in the article's Creative Commons licence, unless indicated otherwise in a credit line to the material. If material is not included in the article's Creative Commons licence and your intended use is not permitted by statutory regulation or exceeds the permitted use, you will need to obtain permission directly from the copyright holder. To view a copy of this licence, visit http://creativecommons.org/licenses/by/4.0/.

(c) The Author(s) 2021 